\title{
TTR
}

Traduction, terminologie, re?daction

\section{Luise von Flotow. Translation and Gender. Translating in the 'Era of Feminism'. Manchester, St Jerome Publishing and Ottawa, University of Ottawa Press, 1997.}

\section{Christine Klein-Lataud}

Volume 11, numéro 1, 1er semestre 1998

Diachronie et synchronie

Diachronics and Synchronics

URI : https://id.erudit.org/iderudit/037324ar

DOI : https://doi.org/10.7202/037324ar

Aller au sommaire du numéro

Éditeur(s)

Association canadienne de traductologie

ISSN

0835-8443 (imprimé)

1708-2188 (numérique)

Découvrir la revue

Citer ce compte rendu

Klein-Lataud, C. (1998). Compte rendu de [Luise von Flotow. Translation and Gender. Translating in the 'Era of Feminism'. Manchester, St Jerome Publishing and Ottawa, University of Ottawa Press, 1997.] TTR, 11(1), 251-252.

https://doi.org/10.7202/037324ar d'utilisation que vous pouvez consulter en ligne.

https://apropos.erudit.org/fr/usagers/politique-dutilisation/ 


\section{COMPTES RENDUS}

\section{Luise von Flotow. Translation and Gender. Translating in the 'Era of Feminism'. Manchester, St Jerome Publishing and Ottawa, University of Ottawa Press, 1997.}

Au confluent des études féministes et de la traductologie, la " traduction au féminin " est un terrain propice aux recherches. Après Gender in Translation, de Sherry Simon (London and New York, Routledge, 1996), le livre de Luise von Flotow nous offre une exploration systématique des pratiques féministes de la traduction et des problèmes critiques qu'elles soulèvent.

En six chapitres plus une conclusion, cette étude expose les bases historiques du mouvement (apparition de la notion de gender, inscription du sujet féminin dans la langue), décrit les pratiques de traduction féministe, en montre les conséquences pour la théorie de la traduction, analyse certaines retraductions féministes (en particulier celles de la Bible et de Simone de Beauvoir), passe en revue les critiques adressées à l'activisme féministe en traduction et termine en ouvrant des perspectives d'avenir. Une petit glossaire et une solide bibliographie complètent l'ensemble.

Illustrée par des exemples nombreux, variés, intéressants, l'étude fait état aussi bien des travaux menés en Europe qu'en Amérique du Nord, (elle s'appuie partiellement sur des communications faites lors de la conférence en 1995 de la Société européenne de traductologie). Le terrain couvert par cette centaine de pages est vaste, mais d'une part, l'auteure a un style concis, grâce auquel elle parvient à transmettre avec clarté une information pourtant riche; d'autre part, elle ne prétend pas à l'exhaustivité. Elle nous brosse la géographie générale de la traduction féministe, indiquant les terrains qu'elle invite à explorer plus avant. Le lectorat étudiant, en particulier, y trouvera de nombreuses pistes de recherche. Le chapitre 6 propose en effet des séries de questions regroupées autour de grands thèmes : rôle des traductrices dans l'histoire, politisation de la traduction, aspects techniques de l'écriture et de la traduction féministes, réception et étude de marché, différences culturelles, politique linguistique des gouvernements, etc. 
Livre stimulant, on le voit, qui constitue une invitation à de multiples voyages aussi bien dans les textes à découvrir ou redécouvrir que dans l'histoire et les théories de la traduction.

Christine Klein-Lataud Université York, Toronto 